\title{
Production of poly(3-hydroxybutyrate) by Halomonas boliviensis in an air-lift reactor
}

\author{
Paola Rivera-Terceros ${ }^{1}$, Estefanía Tito-Claros ${ }^{1 \wedge}$, Sonia Torrico ${ }^{2}$, Sergio Carballo ${ }^{3}$, Doan Van-Thuoc ${ }^{4}$ \\ and Jorge Quillaguamán ${ }^{* *}$
}

\begin{abstract}
Background: Microbial polyesters, also known as polyhydroxyalkanoates (PHAs), closely resemble physical and mechanical features of petroleum derived plastics. Recombinant Escherichia coli strains are being used in industrial production of PHAs in Stirred Tank Bioreactors (STRs). However, use of Air-Lift Reactors (ALRs) has been known to offer numerous technical operating options over STRs, and as such has been successfully implemented in many bioprocesses. Halomonas boliviensis is a halophilic bacterium that is known to assimilate various carbohydrates and convert them into a particular type of PHA known as poly(3-hydroxybutyrate) (PHB). Owing to this capability, it has been used to synthesize the polyester using hydrolysates of starch or wheat bran in stirred tank bioreactors.

Results: This research article firstly describes the production of PHB in shake flasks by H. boliviensis using different combinations of carbohydrates and partially hydrolyzed starch as carbon sources. The highest PHB yields, between 56 and $61 \%$ (wt.), were achieved when either starch hydrolysate or a mixture of glucose and xylose were used as carbon sources. The starch hydrolysate obtained in this study was then used as carbon source in an ALR. The largest amount of PHB, 41 \% (wt.), was attained after 24 hrs of cultivation during which maltose in the hydrolysate was assimilated more rapidly than glucose during active cell growth; however, the rate of assimilation of both the carbohydrates was found to be similar during synthesis of PHB. An incomplete pentose phosphate pathway, which lacks 6-phosphogluconate dehydrogenase, was deduced from the genome sequence of this bacterium and may result in the characteristic assimilation of glucose and maltose by the cells.
\end{abstract}

Conclusions: This study showed that the production of PHB by H. boliviensis using cheap substrates such as starch hydrolysate in a simple production system involving an ALR is feasible. Both maltose and glucose in the hydrolysate induce cell growth and PHB synthesis; most likely the cells balance adequately CoA and NAD(P)H during the assimilation of these carbohydrates. The combination of cheap substrates, simple production systems and the use of non-strict sterile conditions by the halophile $H$. boliviensis are desirable traits for large scale production of PHB, and should lead to a competitive bioprocess.

Keywords: PHB production, Air-lift bioreactor, Starch hydrolysate, Halophile, Halomonas boliviensis

\section{Background}

Microbial polyesters, also known as polyhydroxyalkanoates (PHAs), are biodegradable plastic-like materials whose physical and mechanical features closely resemble those of petroleum derived plastics such as polyethylene and polystyrene [1]. PHAs are synthesized by microorganisms, as carbon and energy storage compounds, from

\footnotetext{
* Correspondence: jorgeqs@supernet.com.bo

Deceased

${ }^{1}$ Center of Biotechnology, Faculty of Sciences and Technology, San Simon University, Cochabamba, Bolivia

Full list of author information is available at the end of the article
}

renewable sources such as carbohydrates and fatty acids $[1,2]$; therefore PHAs have found applications in fine chemistry, biofuels, nanotechnology and biomedicine [2, 3]. A carbon source in excess and the depletion of an essential nutrient, such as nitrogen, phosphorus or oxygen, in the medium usually induce the polymer synthesis in individual cells [1]. Large scale production of PHAs has been attained; however, the commercial competitiveness of PHAs has encountered its main drawback in elevated processing costs, which have been related to the polymer yield reached by a microorganism, carbon source employed, production system and polymer purification $[1,2]$.
() Biomed Central

(c) 2015 Rivera-Terceros et al. Open Access This article is distributed under the terms of the Creative Commons Attribution 4.0 International License (http://creativecommons.org/licenses/by/4.0/), which permits unrestricted use, distribution, and reproduction in any medium, provided you give appropriate credit to the original author(s) and the source, provide a link to the Creative Commons license, and indicate if changes were made. The Creative Commons Public Domain Dedication waiver (http://creativecommons.org/publicdomain/zero/1.0/) applies to the data made available in this article, unless otherwise stated. 
Recombinant Escherichia coli strains are being used in industrial production of PHAs in which stirred tank bioreactors are fed with glucose or sucrose as the main carbon source for cell growth and PHA production [2]. There are nonetheless other bacterial strains that are considered good candidates for large scale production of PHAs, among them Cupriavidus necator (formerly named Ralstonia eutropha), Azohydromonas australica (formerly known as Alcaligenes latus), Pseudomonas spp. and Bacillus spp. [2, 4]. These microorganisms are known to reach PHA yields of 60-88 \% (wt.) in bioreactors operated under a fed-batch mode $[1,2]$. Recently, members of the family Halomonadaceae, such as Halomonas boliviensis [5], Halomonas sp. TD01 [6] and Halomonas sp. KM-1 [7], have been found to accumulate large amounts of PHAs from various carbon sources. These Halomonas species require $\mathrm{NaCl}$ in concentrations ranging from 1 to $8 \%(\mathrm{w} / \mathrm{v})$ for optimum growth, because they are halophilic microorganisms [8]. High salt concentrations in culture media inhibit the growth of non-halophilic microorganisms, thereby leading to production processes that do not require strict sterile conditions $[6,9]$. Consequently, costs involved in the energy consumption intended for the sterilization of bioreactors and tubings should decrease [9]. Hitherto, the highest volumetric productivities achieved by Halomonas spp. have been obtained using Stirred Tank Reactors (STRs) [5].

Use of Air-Lift Reactors (ALRs), on the other hand, is known to offer numerous technical options over STRs, and such has been successfully implemented in various bioprocesses [10, 11]. For example, ALRs containing the proliferating microorganisms are pneumatically mixed by air bubbles pumped through the liquid culture media [10], thus providing an alternative to the rotating shaft or impellers used in STRs [10]. Advantages associated with ARLs include low shear stress, simplicity of design and construction, and low energy requirement for mass transfer [10]. ALRs may hence reduce construction and operation costs [10]. ALRs have been used to culture $C$. necator [12], Burkholderia sacchari [13] and A. australica [14] for poly(3-hydroxybutyrate) (PHB), the most common type of the PHAs, production. Cupriavidus necator reached high $\mathrm{PHB}$ contents, $70 \%$ (wt.), when a combination of glucose and sucrose was used as carbon sources and an air flow rate of at least $35 \mathrm{~L} \mathrm{~min}^{-1}$ was supplied to the reactor - PHB accumulation in C. necator cells was reduced below such air flow rate [12]. Using a step-wise addition of sucrose in an ALR, B. sacchari achieved a high cell density (cell dry weight, CDW, $150 \mathrm{~g} \mathrm{~L}^{-1}$ ) [13], but a lower PHB yield [42 \% (wt.)] than C. necator [12]. On the other hand, A. australica was able to store up to $73 \%$ (wt.) PHB intracellularly upon achieving a CDW of $10.8 \mathrm{~g} \mathrm{~L}^{-1}$ [14]. These reports have shown the feasibility of the production of PHAs in ALRs.

Halomonas boliviensis is a gammaproteobacterium that is known to assimilate and convert various carbohydrates into PHB [15]. Owing to this capability, it has been used to synthesize the polyester using hydrolysates of starch [16] or wheat bran [17]. The PHB accumulation in the cells was between 30-56 \% (wt.) induced by the limitation of yeast extract that was used as the nitrogen source in the culture medium $[16,17]$. Furthermore, $H$. boliviensis also produces large amounts of PHB when the synthesis of the polymer is triggered by the depletion of monosodium glutamate (MSG), which was used as a much cheaper nitrogen source than yeast extract [5]. Studies on the genome sequence of the bacterium suggest that maltose is first assimilated by action of an $\alpha$ glucosidase, before it is metabolized via the glycolytic pathway [18]. On the other hand, the assimilation of glucose by $H$. boliviensis has not been described yet. Both glucose and maltose can be encountered in starch hydrolysates of agricultural residues [16], which are regarded as inexpensive and suitable substrates for PHA production. To understand the metabolic routes that allow the assimilation of such carbohydrates by a microorganism for polyester production is hence important.

This research article describes the production of $\mathrm{PHB}$ by $H$. boliviensis using combinations of glucose, xylose and maltose as carbon sources, and MSG as the nitrogen limiting nutrient in the culture medium. Halomonas boliviensis was also grown in an ALR containing starch hydrolysate. The hydrolysate was employed as the main carbon source for production of PHB. Moreover, the assimilation of glucose in the Entner-Doudoroff and the pentose phosphate pathways was deduced from an evolutionary analysis of the genome of this bacterium.

\section{Results \\ Production of PHB by $\mathrm{H}$. boliviensis using different carbohydrates}

This set of experiments was performed in shake flasks containing $\mathrm{PHB}$ production medium at $35{ }^{\circ} \mathrm{C}$ and $200 \mathrm{rpm}$ for 30 hrs. MSG was used as the nitrogen limiting source at a concentration of $0.2 \%(\mathrm{w} / \mathrm{v})$ as determined previously [18]. As shown in Table 1, mixtures of carbohydrates such as those obtained from partially hydrolyzed starch [16] and wheat bran [17], the starch hydrolysate used in this study, and a combination of the starch hydrolysate and xylose were used as carbon sources for PHB production. The highest CDW was reached when starch hydrolysate was utilized as carbon source, whilst the lowest CDW was attained when a combination of both glucose and maltose was included in the culture medium (Table 1). The mixtures of glucose and xylose or starch hydrolysate and xylose led to similar CDW values (Table 1). 
Table 1 Cell growth and PHB production attained by $\mathrm{H}$. boliviensis in shake flasks using different carbon sources. Samples were withdrawn after $30 \mathrm{~h}$ of cultivation. The experiments were performed in triplicate at a temperature of $35^{\circ} \mathrm{C}$ and an agitation speed of 200 rpm; standard deviations of the mean values are shown in parentheses. Abbreviations refer to cell dry weight (CDW) and residual cell mass (RCM)

\begin{tabular}{|c|c|c|c|c|}
\hline \multirow[t]{2}{*}{ Carbon source } & CDW & $\mathrm{PHB}$ & Volumetric productivity & $\mathrm{RCM}$ \\
\hline & $(g / L)$ & wt.\% & $\mathrm{g} / \mathrm{L} / \mathrm{h}$ & $(g / L)$ \\
\hline Glucose and xylose & $8.1( \pm 0.2)$ & $61( \pm 2.7)$ & 0.15 & 3.2 \\
\hline Glucose and maltose (weight ratio of $0.7: 0.3$ ) & $7.0( \pm 0.1)$ & $53( \pm 3.0)$ & 0.12 & 3.3 \\
\hline Starch hydrolysate and xylose & $8.3( \pm 0.1)$ & $45( \pm 1.1)$ & 0.12 & 4.6 \\
\hline Starch hydrolysate & $9.2( \pm 0.3)$ & $56( \pm 2.6)$ & 0.16 & 4.1 \\
\hline
\end{tabular}

Moreover, the highest PHB yields, between 56 and $61 \%$ (wt.) (Table 1), were achieved when either starch hydrolysate or the mixture of glucose and xylose were used as carbon sources. Furthermore, the high Residual Cell Mass (RCM) and PHB volumetric productivity obtained when the starch hydrolysate was used as a source for PHB production suggest that it also favors both cell growth and PHB synthesis (Table 1).

\section{PHB production by $H$. boliviensis in an ALR}

Starch hydrolysate was used as carbon source in an ALR (Fig. 1). CDW, PHB accumulation, RCM, and glucose and maltose consumed by the bacterium as a function of production time are shown in Fig. 2. Glucose and maltose in the starch hydrolysate were rapidly assimilated and used mainly in the formation of cell biomass up to the first $12 \mathrm{hrs}$ of cultivation; during this time period, $H$. boliviensis yielded only $10.5 \%$ (wt.) PHB (Fig. 2), with maltose being assimilated faster than glucose. Between 12 and 24 hrs of cultivation, glucose and maltose were consumed at almost the same rate, with concomitant increase in $\mathrm{PHB}$ production that reached a maximum of $41 \%$ (wt.) (Fig. 2). The onset of PHB depolymerization coincided with low concentrations of glucose and maltose in the medium. During this time, cells continued to grow as observed by the increase in RCM, although they were only using glucose as carbon source.

\section{Assimilation of carbohydrates by $\mathrm{H}$. boliviensis by the Entner-Doudoroff and pentose phosphate pathways}

The rate of consumption of glucose and maltose in the starch hydrolysate by $H$. boliviensis had distinctive patterns during both cell growth and polymer production (Fig. 2). The genome sequence of $H$. boliviensis was studied in order to determine the biochemical pathways in which these carbohydrates are assimilated. Enzymes involved in the Entner-Doudoroff (E-D) and pentose phosphate (PP) pathways were found to be involved (Fig. 3). Glucose is metabolized through the E-D pathway which initially involves two alleles of putative quinoprotein glucose dehydrogenases (E.C. 1.1.5.2), (Fig. 3, Table 2). A phylogenetic analysis of the protein sequences of these

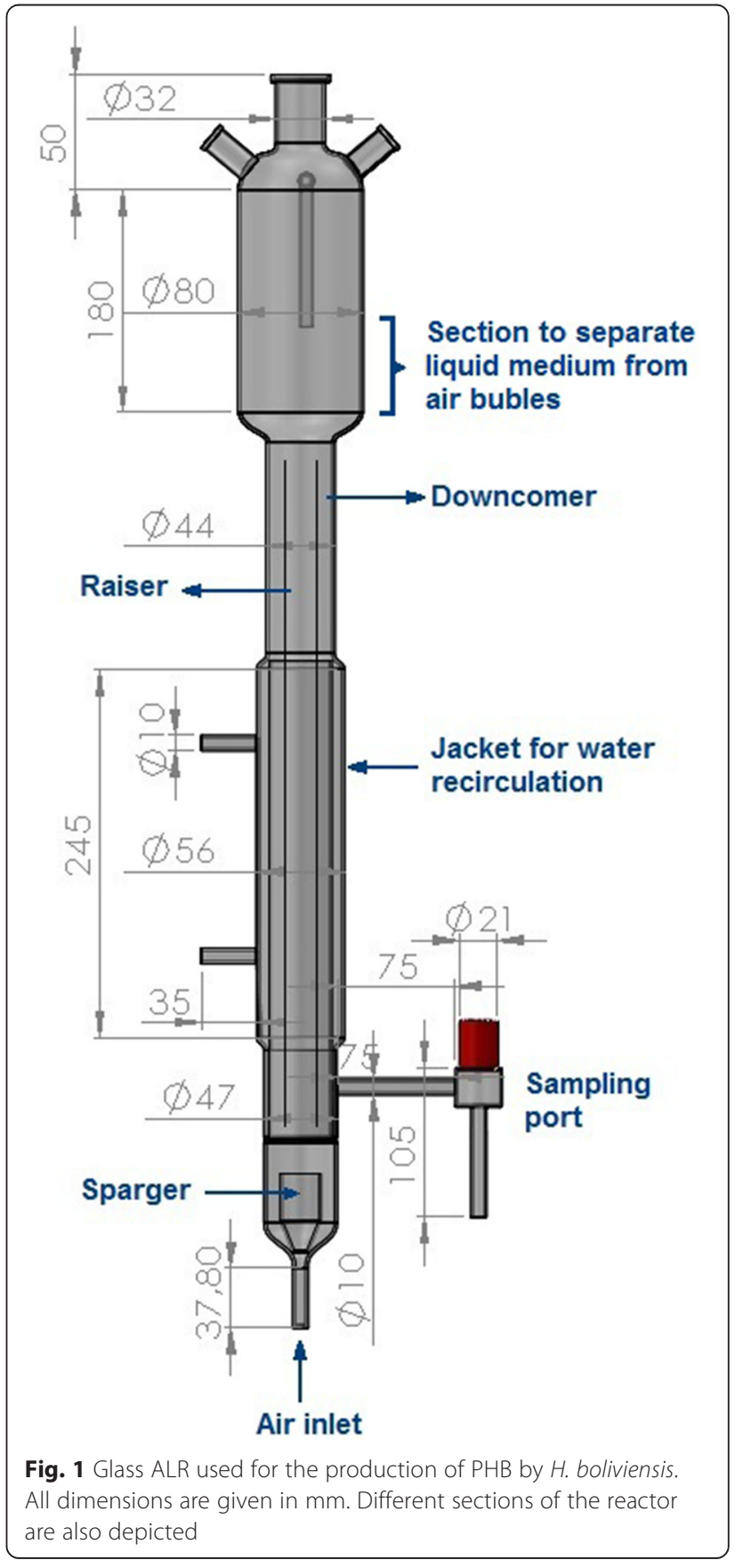




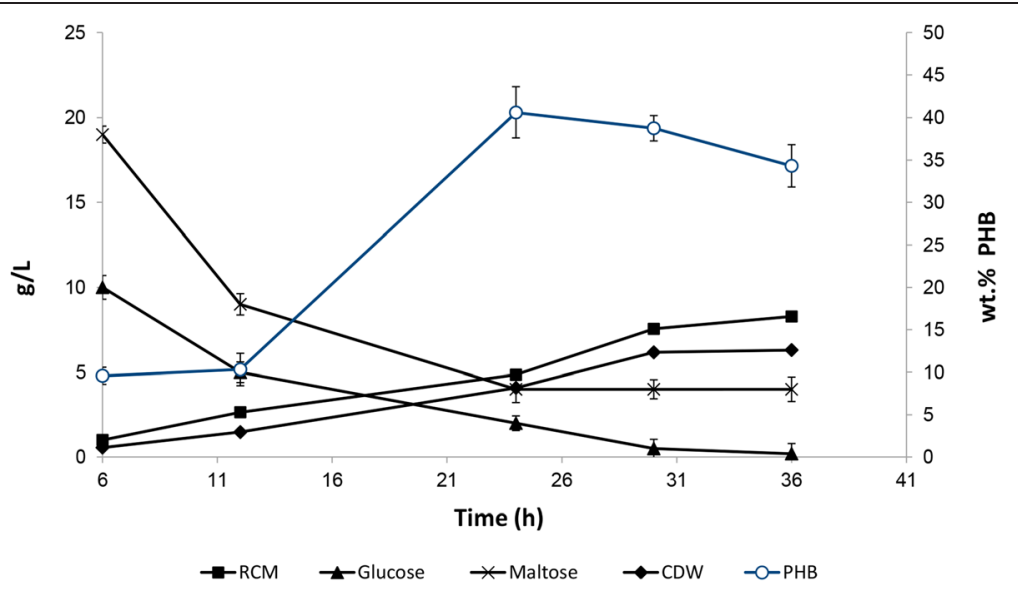

Fig. 2 Cell growth, PHB production, and carbohydrate uptake by H. boliviensis as a function of production time in an ALR operated in a batch system. Air flow rate into the reactor was set at $2.0 \mathrm{~L} \mathrm{~min}{ }^{-1}, \mathrm{pH}$ was maintained at $7.5 \pm 0.3$ and water at $35^{\circ} \mathrm{C}$ was circulated by the jacket of the reactor. The initial MSG concentration was $2 \mathrm{~g} \mathrm{~L}^{-1}$. The experiments were performed in triplicate

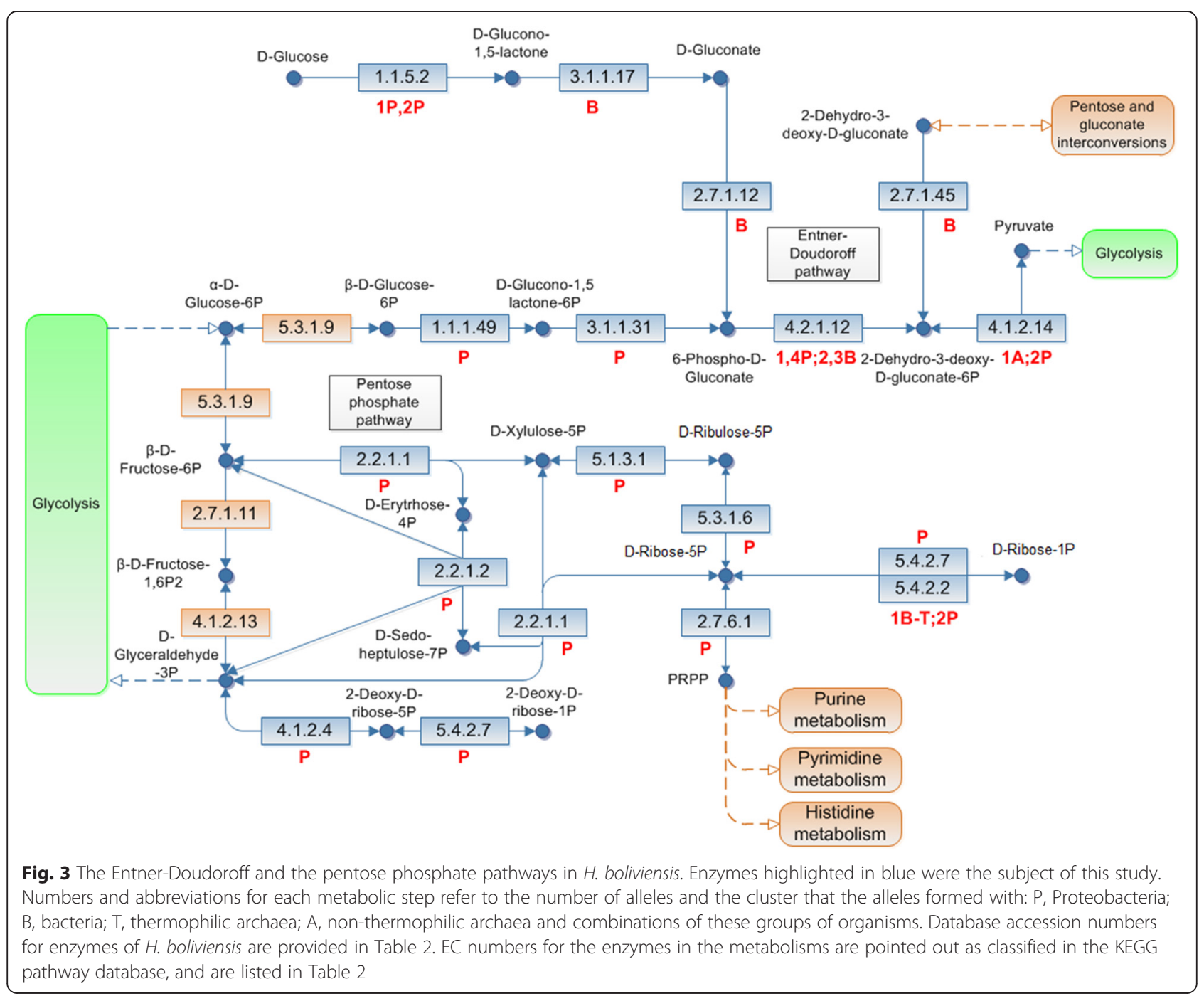


Table 2 Enzymes present in the pentose phosphate pathway of strains of the family Halomonadaceae. Enzymes and their alleles in H. boliviensis were taken as reference; public data base accession numbers for these enzymes are also shown in the table. Correspondingly enzymes and alleles were sought in Halomonas sp. TD01, H. elongata and C. salexigens. Symbols refer to: +, the enzyme is present in a phylogenetic cluster with $\mathrm{H}$. boliviensis and -, the enzyme is absent in a phylogenetic cluster with $\mathrm{H}$. boliviensis

\begin{tabular}{|c|c|c|c|c|c|c|c|}
\hline Enzyme & E.C. number & Accession number & COG & $\begin{array}{l}\text { Alleles in } \\
\text { H. boliviensis }\end{array}$ & $\begin{array}{l}\text { Halomonas sp. } \\
\text { TD01 }\end{array}$ & H. elongata & C. salexigens \\
\hline \multirow[t]{2}{*}{ Quinoprotein glucose dehydrogenase } & 1.1.5.2 & WP_007112539 & 4993 & 1 & + & - & - \\
\hline & & WP_007111394 & & 2 & + & - & - \\
\hline Gluconolactonase & 3.1.1.17 & WP_007113046 & 3386 & 1 & - & - & - \\
\hline Gluconokinase & 2.7.1.12 & WP_007111165 & 3265 & 1 & + & - & + \\
\hline \multirow[t]{4}{*}{ Phosphogluconate dehydratase } & 4.2.1.12 & WP_007112813 & 0129 & 1 & - & + & + \\
\hline & & WP_007114498 & & 2 & + & + & - \\
\hline & & WP_007113381 & & 3 & + & + & + \\
\hline & & WP_007113033 & & 4 & + & + & + \\
\hline \multirow[t]{3}{*}{ 2-dehydro-3-deoxygluconokinase } & 2.7.1.45 & WP_007112577 & 0524 & 1 & + & + & - \\
\hline & & WP_007114584 & & 2 & - & + & + \\
\hline & & WP_007113036 & & 3 & + & + & + \\
\hline \multirow[t]{2}{*}{ 2-dehydro-3- deoxyphosphogluconate aldolase } & 4.1.2.14 & WP_007113045 & 0800 & 1 & - & - & - \\
\hline & & WP_007113048 & & 2 & + & + & + \\
\hline 6-phosphogluconolactonase & 3.1.1.31 & WP_007113049 & 0363 & 1 & + & + & + \\
\hline Glucose-6-phosphate 1-dehydrogenase & 1.1.1.49 & WP_007113050 & 0364 & 1 & + & + & + \\
\hline Transketolase & 2.2.1.1 & WP_007112132 & 0021 & 1 & + & + & + \\
\hline Transaldolase & 2.2 .1 .2 & WP_007111145 & 0176 & 1 & - & + & + \\
\hline Ribulose-phosphate 3-epimerase & 5.1.3.1 & WP_007113254 & 0036 & 1 & + & + & + \\
\hline Ribose 5-phosphate isomerase & 5.3.1.6 & WP_007112167 & 0120 & 1 & + & + & + \\
\hline Deoxyribose-phosphate aldolase & 4.1.2.4 & WP_007111255 & 0274 & 1 & + & + & + \\
\hline Phosphopentomutase & 5.4 .2 .7 & WP_007111257 & 1015 & 1 & + & + & - \\
\hline Ribose-phosphate pyrophosphokinase & 2.7.6.1 & WP_007113450 & 0462 & 1 & + & + & + \\
\hline \multirow[t]{2}{*}{ Phosphoglucomutase } & 5.4 .2 .2 & WP_007111739 & 1109 & 1 & + & + & + \\
\hline & & WP_007111831 & & 2 & - & + & + \\
\hline
\end{tabular}

alleles revealed that they have diverged among enzymes of other Proteobacteria (Additional file 1: Figure S1). This phylogenetic cluster also included two alleles found in Halomonas sp. TD01 (Additional file 1: Figure S1); however the alleles in $H$. boliviensis did not share an evolutionary relationship with enzymes of $H$. elongata and $C$. salexigens (Additional file 1: Figure S1, Table 2). The E-D pathway in $H$. boliviensis continues with a gluconolactonase (E.C. 3.1.1.17) (Fig. 3) that formed a phylogenetic group with gluconolactonases belonging to bacteria not included among the Proteobacteria (Additional file 2: Figure S2, Table 2). Similar evolutionary analyses were performed on the remaining enzymes of the E-D pathway. Some of these enzymes have evolved along with enzymes of bacteria non-taxonomically related to $H$. boliviensis, and some enzymes have even diverged together with enzymes of archaea (Fig. 3).

Halomonas boliviensis may take up glucose by a phosphotransferase - phosphoenol pyruvate - system which phosphorylates the sugar into D-glucose-6-phosphate (G6P) (Enzyme database accession number: WP_007113062) and/ or it may transport glucose by an $\mathrm{ABC}$ multisugar transport system (Enzymes database accession numbers: WP_007113038, WP_040480617, WP_007113040, WP_007113041) (data not shown). Moreover, it was previously reported that other carbohydrates such as maltose and sucrose should yield G6P in H. boliviensis [18]. G6P can continue through the E-D pathway by the action of a glucose-6-phosphate-1-deshydrogenase (E.C. 1.1.1.49) and a 6-phosphogluconolactonase (E.C. 3.1.1.31) (Fig. 3). G6P should also initiate the glycolysis and the pentose phosphate (PP) pathway (Fig. 3). The PP pathway results in the synthesis of two important intermediates: ribose-5phosphate (R5P), used in the synthesis of nucleotides and nucleic acids, and erytrose-4-phosphate (E4P), used in the synthesis of aromatic amino acids. Importantly, we did not find genes related to the expression of 6-phosphogluconate dehydrogenase (E.C. 1.1.1.43); this enzyme allows the 
conversion of 6-phospho-D-gluconate into R5P together with the generation of a molecule of NADPH, whereby Dglucose assimilation cannot be transformed to R5P neither via the E-D pathway nor via the PP pathway (Fig. 3). Furthermore, our evolutionary studies showed that all enzymes of $H$. boliviensis in the PP pathway have evolved within phylogenetic clusters along with enzymes of other Proteobacteria (Fig. 3), and most of these enzymes were included in the same cluster with enzymes found in Halomonas sp. TD01 and Halomonas elongata (Table 2).

\section{Discussion}

Halomonas boliviensis is a halophilic bacterium that is known to produce large amounts of PHB when cultured using carbon sources such as glucose, sucrose, butyric acid, acetate and others [15]. Nevertheless, cheap carbon sources such as hydrolysates of agroindustrial residues are usually composed by a combination of carbohydrates $[16,17]$. Therefore a combination of different sugars and starch hydrolysate were used in our experiments (Table 1). We hydrolyzed cassava starch using Fungamyl - an $\alpha-$ amylase that is commonly utilized in industrial processes to partially hydrolyse starch. We also considered that complete hydrolysis of starch into glucose was not necessary, since $H$. boliviensis is able to assimilate both glucose and maltose [16]. Hence, controlled hydrolysis was carried out to obtain a hydrolysate containing glucose and maltose in a weight ratio of 1:2. We also used sodium glutamate as a cheap nitrogen source that limits cell growth after its depletion from the culture medium. Starch hydrolysate induced both cell growth and PHB accumulation (Table 1), whereas the combination of glucose and maltose at a weight ratio of 0.7:0.3 decreased, to some extent, cell biomass and PHB yield (Table 1). Reports show that $H$. boliviensis is able to attain $9 \mathrm{~g} \mathrm{~L}^{-1} \mathrm{CDW}$ and $55 \%$ (wt.) PHB when yeast extract is used as nitrogen source, whilst 30$56 \%$ (wt.) PHB is found in the cells when starch or wheat hydrolysates are used as the carbon source $[16,17]$. The report also indicates that use of maltose as sole carbon source by the microorganism enable it to accumulate of 58.8 \% (wt.) PHB [16]. Amounts of PHB produced in this study and those accomplished when using yeast extract is used as nitrogen source are similar. Therefore, partially hydrolyzed starch and MSG can be used as cheap carbon and nitrogen sources for PHB synthesis by H. boliviensis (Table 1).

A simple and efficient PHB production system is as important as the availability of cheap carbon and nitrogen sources. Therefore we designed and built an ALR with a simple configuration (Fig. 1). Cells were then cultured in the reactor for PHB production using starch hydrolysate and MSG. Temperature, $\mathrm{pH}$ and air flow into the reactor were controlled during the process. The maximum PHB content reached in our experiments, i.e.
$41 \%$ (wt.) (Fig. 2), was similar to that reported for $B$. sacchari [13], but was lower than those found in $C$. necator [12] and A. australica [14], 70-73\% (wt.). In all cases, the microorganisms were cultivated in ALR. The maximum CDW attained by $H$. boliviensis was $12.3 \mathrm{~g} \mathrm{~L}^{-1}$, similar to that reported for A. australica $\left(10.8 \mathrm{~g} \mathrm{~L}^{-1}\right)$ [14]. Burkholderia sacchari reached a very high cell density $\left(150 \mathrm{~g} \mathrm{~L}^{-1}\right)$, although step-wise addition of sucrose solution into the reactor was involved [13]. In fed-batch fermentations using STRs, $H$. boliviensis has been reported to attain higher cell concentrations and PHB contents than in the ALR [5]. An excess of a carbon source in the culture medium of a PHB producing microorganism is a prerequisite for optimum production of the polymer, therefore glucose or an appropriate ratio of glucose and maltose (Fig. 2) fed to the ALR during the PHB production phase may improve cell growth and PHB yield.

An increase in the value of RCM during cell growth of $H$. boliviensis suggests that the cells were producing PHB while they were still growing. Azohydromonas australica grows, while it synthesizes PHB [14]; however, this is rarely observed in other microorganisms [1]. The growth of $H$. boliviensis was not as fast as that observed in A. australica, but the former commonly produces PHB while the RCM is constant [15]. Indeed, $H$. boliviensis did not grow during the production of $\mathrm{PHB}$ when a sole carbon source such as glucose or butyric acid was included in its culture medium [15], albeit the RCM showed a similar trend to that found in Fig. 1, when a mixture of sucrose and glucose was used in the production process [18]. The intracellular concentrations of CoA, NADPH and NADH have been shown to play crucial roles in both cell growth and PHB synthesis [19]. For example, high concentrations of CoA, usually found during active growth of Methylobacterium rhodesianum, strongly inhibited PHB synthesis, whereas cell growth was hindered by large amounts of NADH due to its inhibitive effect on citrate synthase; furthermore, the $\mathrm{NADPH}$ concentration had to be sufficiently high to prompt the synthesis of the polyester [19]. Methylobacterium rhodesianum produces PHB during its stationary phase of growth when the cells are grown on methanol [20]. However, when cultures of M. rhodesianum were first grown on methanol and then shifted to fructose, they were found to produce PHB during the cell growth [20]. In these experiments, the intracellular concentration of CoA decreased from a high value during the cell growth on methanol to a low value after the shift to fructose [20]. Different carbon sources may be metabolized through distinct pathways, which may lead to different intracellular concentrations of the reducing energy equivalents $[\mathrm{NAD}(\mathrm{P}) \mathrm{H}]$ and $\mathrm{CoA}$. The combination of carbohydrates used as carbon sources for the 
growth of H. boliviensis (Fig. 2) appears to balance the intracellular energy and CoA concentrations so that cell growth and PHB synthesis proceed simultaneously.

The evolutionary trends of all enzymes involved in the E-D and PP pathways in $H$. boliviensis revealed that most enzymes evolved in phylogenetic clusters formed by proteins from other halomonads (Table 2) and Proteobacteria (Fig. 3). Halomonas boliviensis is a gammaproteobacterium, hence its enzymes should be phylogentically related to other enzymes found in Proteobacteria. This however is not the case with gluconolactonase and a gluconokinase at the third and second steps of the PP pathway in $H$. boliviensis. These enzymes appear to have evolved in groups from enzymes belonging to nontaxonomically related bacteria (e.g., Additional file 2: Figure S2), implying that they, together with those that clustered with archaeal enzymes, were acquired by horizontal gene transfer (HGT) [18, 21]. HGT was also found in the glycolytic pathway of $H$. boliviensis [18]. The fourth step in the PP pathway is catalyzed by a 6-phosphogluconate dehydrogenase (E.C. 1.1.1.43), which is absent in H. boliviensis. This enzyme has proven to play an important role in bacterial cell growth; for instance, mutants of Gluconobacter oxydans [22] and Pseudomonas cepacia [23] deficient in 6-phosphogluconate dehydrogenase showed growth inhibition when mannitol and glucose were used as carbon sources, respectively. Halomonas boliviensis seems to have overcome the lack of this enzyme by favoring a rapid assimilation of maltose (Fig. 2) via the glycolysis, leading to the generation of precursors of nucleotides, nucleic acids and aromatic amino acids in the PP pathway. A molecule of glucose yields 1 ATP, $1 \mathrm{NADH}$ and $1 \mathrm{NADPH}$ in the ED pathway. By comparison, glycolysis has a net yield of 2 ATP and $2 \mathrm{NADH}$. Assimilation of glucose and maltose in both of these cellular metabolic routes appears to equilibrate the intracellular energy for PHB production and anabolism (Fig. 2). Moreover, PHB depolymerization, which commonly involves hydrolysis of ATP, requires a less amount of energy than an anabolic metabolism, and only demanded the assimilation of glucose by $H$. boliviensis (Fig. 2); this sugar may have been assimilated by the E-D pathway because precursors for DNA and amino acids were not as essential as they were during the first $24 \mathrm{hrs}$ of the cultivation during the active cell growth. Further studies are being performed on PHB production in an air-lift reactor that is fed with an automated inflow of carbons sources.

\section{Conclusion}

This study showed that the production of PHB by $H$. boliviensis using cheap substrates such as starch hydrolysate in a simple production system involving an ALR is feasible. Both maltose and glucose in the hydrolysate induce cell growth and PHB synthesis; most likely the cells balance adequately $\mathrm{CoA}$ and $\mathrm{NAD}(\mathrm{P}) \mathrm{H}$ during the assimilation of these carbohydrates. The combination of cheap substrates, simple production systems and the use of non-strict sterile conditions by the halophile $\mathrm{H}$. boliviensis are desirable traits for large scale production of PHB, and should lead to a competitive bioprocess. However, additional studies on air-lift reactors operated under a fed-batch mode are required.

\section{Methods}

\section{Bacterial strain and maintenance}

Halomonas boliviensis $\mathrm{LC}^{\mathrm{T}}$ (= DSM $15516^{\mathrm{T}}$ ) was maintained at $4{ }^{\circ} \mathrm{C}$ on solid $\mathrm{HM}$ medium [15], containing (\%, w/v): $\mathrm{NaCl}, 4.5 ; \mathrm{MgSO}_{4} \cdot 7 \mathrm{H}_{2} \mathrm{O}, 0.025 ; \mathrm{CaCl}_{2} \cdot 2 \mathrm{H}_{2} \mathrm{O}$, 0.009; $\mathrm{KCl}, 0.05 ; \mathrm{NaBr}, 0.006$; peptone, 0.5 ; yeast extract, 1.0; glucose, 0.1 ; and agar, 2.0. The $\mathrm{pH}$ of the medium was adjusted to 7.5 using $3 \mathrm{M} \mathrm{NaOH}$.

\section{Hydrolysis of starch obtained from cassava}

Starch from cassava was suspended in $0.05 \mathrm{M}$ citrate buffer solution $(\mathrm{pH}=6)$ in a stirred tank, after which $\alpha$ amylase, Fungamyl, was added. Hydrolysis of starch was allowed to proceed at $60{ }^{\circ} \mathrm{C}$ and at a stirring speed of $200 \mathrm{rpm}$ for $24 \mathrm{hrs}$. The total sugar concentration in the resulting hydrolysate solution was determined to be $200 \mathrm{~g} \mathrm{~L}^{-1}$ containing mainly glucose and maltose in a weight ratio of $1: 2$.

\section{Culture medium and conditions for PHB production in shake flasks}

Seed culture and PHB production media were formulated as described previously [16]. Seed culture medium contained (\%, w/v): $\mathrm{NaCl}, 2.5 ; \mathrm{MgSO}_{4}{ }^{\circ} 7 \mathrm{H}_{2} \mathrm{O}, 0.25$; $\mathrm{K}_{2} \mathrm{HPO}_{4}, 0.05 ; \mathrm{NH}_{4} \mathrm{Cl}, 0.23 ; \mathrm{FeSO}_{4}{ }^{\circ} 7 \mathrm{H}_{2} \mathrm{O}, 0.005$; glucose, 1.0; monosodium glutamate (MSG), 0.2 and TRIS, 1.5 . The seed culture was at $30{ }^{\circ} \mathrm{C}$ and $200 \mathrm{rpm}$ for $15 \mathrm{hrs}$ $\left(\mathrm{OD}_{600}=0.5-0.55 ; \mathrm{CDW}=1.0 \pm 0.1 \mathrm{~g} \mathrm{~L}^{-1}\right) .5 \%(\mathrm{v} / \mathrm{v})$ was used to inoculate the $\mathrm{PHB}$ production medium, containing (\%, w/v): $\mathrm{NaCl}, 2.5 ; \mathrm{MgSO}_{4}{ }^{\circ} 7 \mathrm{H}_{2} \mathrm{O}, 0.5 ; \mathrm{K}_{2} \mathrm{HPO}_{4}$, 0.22; $\mathrm{NH}_{4} \mathrm{Cl}, 0.4 ; \mathrm{FeSO}_{4}{ }^{\circ} 7 \mathrm{H}_{2} \mathrm{O}, 0.005$; MSG, 0.2; and the following carbohydrates (\%,w/v): 1) 1.5 glucose and 0.5 xylose, 2) 1.4 glucose and 0.6 maltose, 3) 1.5 starch hydrolysate and 0.5 xylose, 4) 2.5 starch hydrolysate, respectively. A low amount, $0.2 \%$ (w/v) MSG, was added to the production medium to induce its depletion by $H$. boliviensis during the cultivation. All experiments were performed in $1000 \mathrm{ml}$ shake flasks at $35^{\circ} \mathrm{C}$ and $200 \mathrm{rpm}$ of agitation.

\section{Air-lift reactor construction and operation for PHB production}

An air-lift glass with geometrical dimensions as depicted in Fig. 1 was used in this study. Air at a flow rate of $2 \mathrm{~L} \mathrm{~min}^{-1}(2.5 \mathrm{vvm})$ was pumped through a millipore 
glass net that acted as air sparger. Air bubbles created by the sparger enter to an inner tube (known as the riser) which is concentrically surrounded by an ungassed inner tube (known as the downcomer). The different gas holdup in the raiser and downcomer zones result in dissimilar bulk densities of the liquid culture medium in these regions which causes circulation of the liquid in the reactor by gas-lift action. On top of the riser and downcomer a column section of $180 \mathrm{~mm}$ height was placed in order to separate air bubbles from the culture medium. The upper most section of the reactor had three openings: the middle one for inserting a $\mathrm{pH}$ electrode and the ones on either side as an air outlet and for addition of acid, base or antifoam to the reactor, respectively. Moreover on one side of the downcomer, and at $105 \mathrm{~mm}$ from the sparger, a sampling device was coupled. A $245 \mathrm{~mm}$ height external jacket was also included in the reactor to maintain the temperature constant by water recirculation.

Halomonas boliviensis was cultured in a $1 \mathrm{~L}$ Erlenmeyer flask containing $50 \mathrm{ml}$ of seed culture medium at $30{ }^{\circ} \mathrm{C}$ for $15 \mathrm{hrs}$. The seed culture was inoculated in $700 \mathrm{ml}$ of $\mathrm{PHB}$ production medium in the reactor and cultivation was allowed to proceed for $36 \mathrm{hrs.} \mathrm{pH}$ of the medium was controlled at $7.5 \pm 0.3$ by adding $3 \mathrm{M}$ $\mathrm{NaOH}$ or $3 \mathrm{M} \mathrm{HCl}$ in the reactor whenever a deviation from the set point value was observed. Water at $35{ }^{\circ} \mathrm{C}$ originating from a thermostatic water bath was recirculated through the jacket of the reactor. Antifoam was added when needed. Samples were withdrawn from the reactor at different time intervals.

\section{Genome sequences studied and evolutionary analysis of proteins}

Four genome sequences corresponding to strains of the family Halomonadaceae were selected for this study. The strains were Halomonas boliviensis $\mathrm{LC}^{\mathrm{T}}$ (=DSM $15516^{\mathrm{T}}$ ) [18], Halomonas elongata DSM $2581^{\mathrm{T}}$ [24], Halomonas sp. TD01 [25], and Chromohalobacter salexigens DSM 3043 [26].

A total of 6901 alignments of clusters of orthologous proteins (COGs) of 88 microorganisms, as classified in COGs [27] and EggNOG [28] databases, were obtained from that described by Puigbò et al. [29]. The protein sequences of these 88 microorganisms were used as reference for the evolutionary analysis. Protein sequences of strains of the family Halomonadaceae were included in the alignments with the references for each corresponding COG using the Muscle program [30] included in the MEGA 5 software package [31] with default parameters. Unrooted maximum likelihood phylogenetic trees for each COG were constructed using MEGA 5 under a WAG with frequencies $(+\mathrm{F})$ model, with uniform mutation rates among amino acid sites and complete deletion of gaps and missing data.

\section{Determination of biochemical pathways}

Halomonas boliviensis was taken as the reference strain for the determination of biochemical pathways. The functional annotation of enzymes involved in the pentose phosphate and Entner-Doudoroff pathways was accomplished by analyses of protein sequences. Genes of $H$. boliviensis were aligned to others in databases to attain its corresponding functional annotation. To ensure the biological meaning, only one high-quality information as annotation to the genes from many results was chosen. BLAST was used to accomplish functional annotation combined with different databases. BLAST version: blastall 2.2.21 software (provided by the National Center for Biotechnology Information) was used for these studies. Alignment results were obtained using the KEGG, COG, SwissProt, TrEMBL, and NR databases. A BLAST search was also used to find enzymes in $H$. elongata, C. salexigens, and Halomonas sp. TD01 that share high identities with those annotated for $H$. boliviensis.

\section{Quantitative analyses}

Cell dry weight (CDW) and PHB content in H. boliviensis were determined as reported previously [15]. Residual cell mass (RCM) concentration was calculated as the difference between the CDW and PHB concentration, while PHB content (wt.\%) was obtained as the percentage of the ratio of $\mathrm{PHB}$ concentration to the CDW as defined by Lee et al. [32]. All analyses were performed in triplicate. Glucose and maltose were determined using the same HPLC system with a Polypore CA column (Perkin-Elmer), a RI detector at $80{ }^{\circ} \mathrm{C}$ and water as mo-

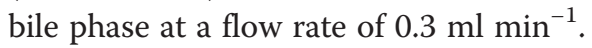

\section{Additional files}

Additional file 1: Figure S1. Phylogentic tree relating clusters of orthologous protein sequences (COGs) corresponding to quinoprotein glucose dehydrogenase COG4993. The tree was constructed under a maximum likelihood approach using MEGA 5 software and the WAG with frequencies (+F) model. GenBank accession numbers of the sequences are given in parentheses. Numbers at branch points are bootstrap values (500 replicates). Bar denotes 0.2 sequence divergence. (PDF 60 kb)

Additional file 2: Figure S2. Phylogentic tree relating clusters of orthologous protein sequences (COGs) corresponding to gluconolactonase COG3386. The tree was constructed under a maximum likelihood approach using MEGA 5 software and the WAG with frequencies (+F) model. GenBank accession numbers of the sequences are given in parentheses. Numbers at branch points are bootstrap values (500 replicates). Bar denotes 0.2 sequence divergence. (PDF $75 \mathrm{~kb}$ )

\section{Competing interests}

The authors declare that they have no competing interests. 


\section{Authors' contributions}

P R-T and JQ performed the evolutionary analyses. E T-C, ST, SC, D V-T and JQ studied the PHB production by $H$. boliviensis. All authors wrote the manuscript and approved the final version.

\section{Acknowledgements}

The authors would like to thank Mr. Kevin Raymond Oluoch at the University of Nairobi for his contribution to this article. We would also like to thank the Swedish International Development Cooperation Agency (Sida), and to the National Foundation for Science and Technology Development (Grant no: 106.03-2010.64) for supporting our research work

\begin{abstract}
Author details
${ }^{1}$ Center of Biotechnology, Faculty of Sciences and Technology, San Simon University, Cochabamba, Bolivia. ${ }^{2}$ Center of Agroindustrial Technology, Faculty of Sciences and Technology, San Simon University, Cochabamba, Bolivia. ${ }^{3}$ Center of Food and Natural Products, Faculty of Sciences and Technology, San Simon University, Cochabamba, Bolivia. ${ }^{4}$ Department of Microbiology and Biotechnology, Faculty of Biology, Hanoi National University of Education, 136 XuanThuy, CauGiay, Hanoi, Vietnam.
\end{abstract}

Received: 21 April 2015 Accepted: 15 July 2015

Published online: 03 August 2015

\section{References}

1. Steinbüchel A, Füchtenbush B. Bacterial and other biological systems for polyester production. Trends Biotechnol. 1998;16:419-27.

2. Philip S, Keshavarz T, Roy I. Polyhydroxyalkanoates: biodegradable polymers with a range of applications. J Chem Technol Biot. 2007:82:233-47.

3. Chen $\mathrm{GQ}$, Wu Q. The application of polyhydroxyalkanoates as tissue engineering materials. Biomaterials. 2005;26:6565-78.

4. Chen GQ, König KH, Lafferty RM. Occurrence of poly-d(-)-3hydroxyalkanoates in the genus Bacillus. FEMS Microbiol Lett. 1991;68:173-6.

5. Quillaguamán J, Doan-Van T, Guzmán H, Guzmán D, Martín J, Akaraonye E, et al. Poly(3-hydroxybutyrate) production by Halomonas boliviensis in fed-batch culture. Appl Microbiol Biotechnol. 2008:78:227-32.

6. Tan D, Xue YS, Aibaidula G, Chen GQ. Unsterile and continuous production of polyhydroxybutyrate by Halomonas TD01. Bioresour Technol. 2011;102:8130-6.

7. Kawata $Y$, Jin $Y X$, Nojiri M. Efficient secretion of (R)-3-hydroxybutyric acid from Halomonas sp. KM-1 cultured with saccharified Japanese cedar under microaerobic conditions. Bioresour Technol. 2013;140:443-5.

8. Oren A. Microbial life at high salt concentrations: phylogenetic and metabolic diversity. Saline Systems. 2008;4:2.

9. Quillaguamán J, Guzmán H, Van-Thuoc D, Hatti-Kaul R. Synthesis and production of polyhydroxyalkanoates by halophiles: current potential and future prospects. Appl Microbiol Biotechnol. 2010;85:1687-96.

10. Chisti MY, Moo-Young M. Airlift reactors: characteristics, applications and design considerations. Chem Eng Comm. 1987;60:195-242.

11. Sajc L, Grubisic D, Vunjak-Novakovic G. Bioreactors for plant engineering: an outlook for further research. Biochem Eng J. 2000;4:89-99.

12. Tavares LZ, da Silva ES, da Cruz Pradella JG. Production of poly(3hydroxybutyrate) in an airlift bioreactor by Ralstonia eutropha. Biochem Eng J. 2004;18:21-31.

13. Pradella JG, Taciro MK, Mateus AY. High-cell-density poly(3-hydroxybutyrate) production from sucrose using Burkholderia sacchari culture in airlift bioreactor. Bioresour Technol. 2010;101:8355-60.

14. Gahlawat G, Sengupta B, Srivastava AK. Enhanced production of poly(3hydroxybutyrate) in a novel airlift reactor with in situ cell retention using Azohydromonas australica. J Ind Microbiol Biotechnol. 2012;39:1377-84.

15. Quillaguamán J, Delgado O, Mattiasson B, Hatti-Kaul R. Poly(Bhydroxybutyrate) production by a moderate halophile, Halomonas boliviensis LC1. Enzyme Microb Tech. 2006:38:148-54.

16. Quillaguamán J, Hashim S, Bento F, Mattiasson B, Hatti-Kaul R. Poly( $\beta$ hydroxybutyrate) production by a moderate halophile, Halomonas boliviensis LC1 using starch hydrolysate as substrate. J Appl Microbiol. 2005:99:151-7.

17. Van-Thuoc D, Quillaguamán J, Mamo G, Mattiasson B. Utilization of agricultural residues for poly(3-hydroxybutyrate) production by Halomonas boliviensis LC1. J Appl Microbiol. 2008;104:420-8.
18. Guzmán D, Balderrama-Subieta A, Cardona-Ortuño O, Guevara-Martínez M, Callisaya-Quispe N, Quillaguamán J. Evolutionary patterns of carbohydrate transport and metabolism in Halomonas boliviensis as derived from its genome sequence: influences on polyester production. Aquat Biosyst. 2012;8:9.

19. Mothes G, Rivera I, Babel W. Competition between $\beta$-ketothiolase and citrate synthase during poly( $\beta$-hydroxybutyrate) synthesis in Methylobacterium rhodesianum. Arch Microbiol. 1996;166:405-10.

20. Mothes G, Ackermann J-U, Babel W. Regulation of poly( $\beta$-hydroxybutyrate) synthesis in Methylobacterium rhodesianum MB 126 growing on methanol or fructose. Arch Microbiol. 1998;169:360-3.

21. Schliep K, Lopez P, Lapointe FJ, Bapteste E. Harvesting evolutionary signals in a forest of prokaryotic gene trees. Mol Biol Evol. 2011;28:1393-405.

22. Richhardt J, Bringer S, Bott M. Mutational analysis of the pentose phosphate and Entner-Doudoroff pathways in Gluconobacter oxydans reveals improved growth of a $\Delta$ edd $\Delta$ eda mutant on mannitol. Appl Environ Microbiol. 2012;78:6975-86.

23. Allenza P, Lessie TG. Pseudomonas cepacia mutants blocked in the EntnerDoudoroff pathway. J Bacteriol. 1982;150:1340-7.

24. Schwibbert K, Marin-Sanguino A, Bagyan I, Heidrich G, Lentzen G, Seitz H, et al. A blueprint of ectoine metabolism from the genome of the industrial producer Halomonas elongata DSM 2581 . Environ Microbiol. 2011;13:1973-94.

25. Cai L, Tan D, Aibaidula G, Dong XR, Chen JC, Tian WD, et al. Comparative genomics study of polyhydroxyalkanoates (PHA) and ectoine relevant genes from Halomonas sp. TD01 revealed extensive horizontal gene transfer events and co-evolutionary relationships. Microb Cell Fact. 2011:10:88.

26. Oren A, Larimer F, Richardson P, Lapidus A, Csonka LN. How to be moderately halophilic with broad salt tolerance: clues from the genome of Chromohalobacter salexigens. Extremophiles. 2005;9:275-9.

27. Tatusov RL, Fedorova ND, Jackson JD, Jacobs AR, Kiryutin EV, Koonin EV et al. The COG database: an updated version includes eukaryotes. BMC Bioinformatics. 2003:4:41.

28. Jensen $\sqcup$, Julien $P$, Kuhn M, von Mering C, Muller J, Doerks T, et al. eggNOG: automated construction and annotation of orthologous groups of genes. Nucleic Acids Res. 2008:36:D250-4.

29. Puigbò $P$, Wolf $Y$, Koonin EV. Search for a 'Tree of Life' in the thicket of the phylogenetic forest. J Biol. 2009:8:59.

30. Edgar RC. MUSCLE: multiple sequence alignment with high accuracy and high throughput. Nucleic Acids Res. 2004;32:1792-7.

31. Tamura K, Peterson D, Peterson N, Stecher G, Nei M, Kumar S. MEGA5: Molecular evolutionary genetics analysis using maximum likelihood, evolutionary distance, and maximum parsimony methods. Mol Biol Evol. 2011;10:2731-9.

32. Lee SY, Wong HH, Choi J, Lee SH, Lee SC, Han CS. Production of mediumchain-length polyhydroxyalkanoates by high-cell-density cultivation of Pseudomonas putida under phosphorus limitation. Biotechnol Bioeng. 2000;68:466-70.

\section{Submit your next manuscript to BioMed Central and take full advantage of:}

- Convenient online submission

- Thorough peer review

- No space constraints or color figure charges

- Immediate publication on acceptance

- Inclusion in PubMed, CAS, Scopus and Google Scholar

- Research which is freely available for redistribution 